\title{
Editorial Note on: Post-exercise heart rate recovery in individuals with spinal cord injury
}

Spinal Cord (2010) 48, 645; doi:10.1038/sc.2010.7; published online 2 February 2010

Editorial Note on: Spinal Cord (2010) 48, 639-644; doi:10.1038/sc.2009.196; published online 2 February 2010

Recently, Mayers et al. ${ }^{1}$ reported on the topic of postexercise heart rate recovery (HRR) in spinal cord injury (SCI) individuals with tetraplegia, high paraplegia (T2-T6) and low paraplegia (T7-S1). The authors attempted to characterize the HRR in SCI individuals relative to ambulatory subjects. They observed a significantly more rapid normalized HRR in SCI individuals than in ambulatory subjects. I read this article with interest because it addresses a very important issue of the disruption of normal autonomic cardiovascular control mechanisms in individuals with SCI during and after exercise. However, I have some reservations regarding the methodology chosen for the study. According to the current state-of-the-art in studies performed in the field of exercise physiology in individuals with $\mathrm{SCI}^{2,3}$ there seems to be a compelling need for standardization of the methodology as well as the strategies and technology used in such studies. The authors used a different testing method for assessing the HRR in individuals with SCI (that is, the maximal arm ergometer exercise test) than in ambulatory subjects (that is, the maximal treadmill exercise test). Unfortunately, it was not taken into account that the arm (upper-body) exercise produces a significantly lower $\mathrm{HR}_{\text {peak }}$ than the leg exercises. ${ }^{4}$ If the ambulatory subjects, who did the leg exercises, are compared with the SCI individuals, who performed arm exercises, one is likely to observe a significantly higher $\mathrm{HR}_{\text {peak }}$ in the ambulatory than in SCI individuals. This may potentially affect the HRR.

\section{$\mathrm{N}$ Morgulec-Adamowicz Department of Adapted Physical Activity, Faculty of Rehabilitation, Józef Pitsudski University of Physical Education, Warsaw, Poland E-mail: natalia.morgulec@awf.edu.pl}

\section{References}

1 Myers JN, Hsu L, Hadley D, Lee MY, Kiratli BJ. Post-exercise heart rate recovery in individuals with spinal cord injury. Spinal Cord 2010; 48: 639-644.

2 Haisma JA, van der Woude LHV, Stam HJ, Bergen MP, Sluis TAR, Bussmann JBJ. Physical capacity in wheelchair-dependent persons with a spinal cord injury: a critical review of the literature. Spinal Cord 2006; 44: 642-652.

3 van der Woude LHV, Veeger HEJ, Dallmeijer AJ, Janssen TWJ, Rozendaal LA. Biomechanics and physiology in active manual wheelchair propulsion. Med Eng Phys 2001; 23: 713-733.

4 McArdle WD, Katch FI, Katch VL. Exercise Physiology, Energy, Nutrition, and Human Performance, 5th edn. Lippincott Williams \& Wilkins: Philadelphia, 2001, p 478. 